stages as done heretofore, thus avoiding several anesthesias, operations, saving time for both patient and surgeon and avoiding subsequent small operations due to failures by the older methods. In the old methods contractions sometimes occur which render the steps of the operations futile. In this operation the dressings are kept clean and dry, there is no soiling with urine, and it is not necessary to pass any instruments; there is no tension on the wound, no skin grafting, and the method is applicable to all cases.

The deeper structures are sutured separately and accurately with burned absorbable stitches so as to get perfect union. This layer of sutures forms a firm barrier, while the superficial layer forms an additional aid to healing. 'The character of the buried suture materials is of importance. Sterilized fine catgut or tendon is the most suitable material for burned sutures. If the animal sutures are aseptic the healing is usually satisfactory. Silk or other non-absorbable materials or too heavily chromicized catgut or tendon should not be used as buried sutures, for, although the wounds may heal primarily, yet later sinus or sinuses form and keep discharging until the suture or suturings are thrown off or removed surgically. Such healing also interferes with nice clean union.

I first performed the operation as above described in San Francisco in November, 1904. The patient was about 30 years of age and was referred to me by Dr. Alfred Sander, of San Francisco. The urethra opened anteriorly to the scrotum, about $21 / 2$ inches back of the glans on the under surface of the body and a little to the left of the median line. 'There was a marked incurvation of the penis which produced considerable inconvenience on urinating as the stream was broken and the patient usually wetted. Coitus was practically impossible, as proper erection and entrance were prevented by the incurvations. Surgery was of great avail; henling was primary and durable; the incurvation was overcome; a new urethra was formed; the glandular and penile urethra were built and anastomosis was made between the ends of the new and old urethras; all raw surfaces were covered over; the operation was finished successfully at one sitting and gave perfect functional results. Examination made a couple of months after the operation showed everything satisfactory and canal of normal caliber. After the operation the patient was kept sufficiently under bromids and chloral to control erections, thus greatly favoring primary healing. 533 Sutter Street.

\section{ERRORS IN THE DETERMINATION OF FREE HYDROCHLORIC ACID.*}

E. L. WHI'TNEY, M.D.

Professor of Physiological Chemistry, Baltimore Medical College. BALTIMORE.

Since Kuhne demonstrated the necessity for free hydrochloric acid in peptic digestion many methods have been devised for its detection and determination. This multiplicity of tests is a good indication that none of them exactly fills the requirements. The tests chiefly recommended for the detection of free hydrochloric acid may be divided into two classes, those depending on the change in color produced in some indicator, such as congo-red, dimethyl-amido-azo-benzol, benzopurpurin, tropeolin 00 and others of similar character, and those

* Read in the Section on Pathology and Physiology of the American Medical Association, at the Fifty-sixth Annual Session, July, 1905. depending on the coloration produced by the acid on certain organic materials, such as the phloroglucinvanillin test of Günzberg and the sugar-resorcin test of Boaz.

Against the class of indicators as a whole we may state that, almost without exception, they give a reaction with the organic acids when present in sufficient concentration, as can be easily shown by testing the solutions of the various organic acids with them, the intensity of the reaction varying, of course, with the strength of the acid employed and the degree of delicacy of the end point of the indicator employed. The effect of the acid salts on the indicators is best shown by attempting to titrate a solution of orthophosphoric acid with decinormal alkali, using any of the indicators. According to theory were they not affected by acid salts, the end point should be reached when exactly one-third of the calculated amount of alkali necessary to neutralize all the hydrogen has been added, a condition by no means fulfilled by any of the indicators with which I have experimented. The same test can also be applied by titrating decinormal sulphuric acid with any of these indicators. Were they actually not affected by an acid salt the amount of decinormal alkali required would be exactly half the amount of decinormal sulphuric acid taken, while the result of the experiment shows that an amount of alkali too great for the formation of the acid salt and not enough for the complete neutralization of the acid hydrogen is required. An added disadvantage is that with many of these indicators the end point is frequently obscure, the operator eren when trained in chemical work being unable to state definitely the end point.

For qualitative work no fault can be found with the tests of Giinzberg and Boaz which give absolutely accurate results.

For quantitative purposes the use of the various indicators is even less reliable than their qualitative indications. As stated under their uses as qualitative tests, they all react to a certain extent with the various organic acids and acid salts and have an indefinite end point. What is still more important with them is their behavior with the so-called combined hydrochloric acid, which is split up as the titration proceeds, the hydrochloric acid and the proteid with which it is combined undergoing a cleavage, the hydrochloric acid thus liberated being also titrated as free hydrochloric: The hydrochloric acid shown by these indicators must, therefore, be composed of the true free hydrochloric acid, varying proportions of the acid salts, and organic acids, and also of a portion of the hydrochloric acid which was originally in combination with the proteids of the gastric contents.

Titration with either the Boaz or Günzberg reagent as an outside indicator requires at least three titrations to insure accurate results, as a considerable amount of the fluid will be used in the preliminary tests outside. In addition they will also show probably at least a small part of the combined hydrochloric acid which splits up as the titration proceeds.

In several years' use of the various indicators $I$ became convinced of the serious errors at times occurring in the ordinary titrations for free hydrochloric acid, titrations showing, for example, a hyperchlorhydria, while the results of treatment did not bear out the results of the titration. When in search of a method which would be free from these sources of error, my attention was called to a method worked out by Hoffmann at Ostwald's suggestion, which seemed to give promise 
of better results, based, as it was, on an entirely different principle. Hoffmann's method was based on the effect of free hydrogen ions in saponifying methyl or ethyl acetate with the formation of free methyl or ethyl alcohol and acetic acid, the amount of the latter being proportional, other things being equal, to the amount of free hydrogen ion present, and readily titrated with decinormal alkali and an indicator such as phenolphthalein.

Considerable experience with this method has led me to make slight changes in it which, I think, give greater accuracy, though the actual difference is not great. As I carry out the method it may be described thus: Four small, clean, dry flasks are prepared and filled as follows:

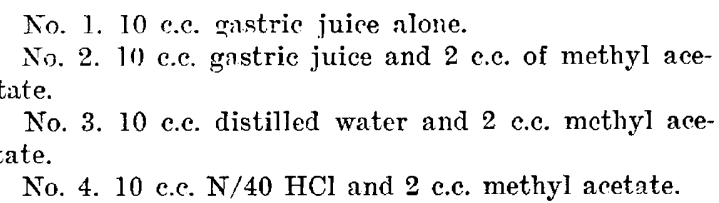

These are tightly stoppered and placed for at least four hours in a hot air bath at a temperature of between 50 and 55 degrees Centigrade, not at any time exceeding 56, the boiling point of methyl acetate. At the end of at least four hours they are removed and the contents titrated with decinormal alkali, using phenolphthalein as an indicator to the first pink tinge.

No. 1 shows the original acidity plus any increase in the acidity due to standing at a high temperature. This increase does not usually occur, but, as it has taken place in a few cases in my work, it seems to me a reasonable precaution.

No. 2 shows the original acidity plus the increase in acidity due to the formation of acetic acid from the methyl acetate.

No. 3 shows the acetic acid produced by the saponifying action of the distilled water and the small amount of acid which is often present in commercial methyl acetate.

No. 4 shows the acidity of the original $\mathrm{N} / 40 \mathrm{HCl}$ plus the acetic acid liberated from the methyl acetate by the hydrochloric acid.

The calculations from these four determinations are simple and may be illustrated by an example from my notebook:

1. 10 c.c. of gastric juice allowed to stand for five hours at a temperature of 55 degrees required 6.2 c.c. of $\mathrm{N} / 10 \mathrm{KOH}$ to give the first pink tinge with phenolphthalein as an indicator.

2. 10 c.c. of gastric juice plus 2 c.c. of methyl acetate under exactly the same conditions required 64.9 c.c. $\mathrm{N} / 10 \mathrm{KOH}$.

3.10 c.c. distilled water plus 2 e.c. methyl acetate under the same conditions required 8.4 c.c. $\mathrm{N} / 10 \mathrm{KOH}$.

4. 10 c.e. $\mathrm{N} / 40 \mathrm{HCl}$ plus 2 c.c. methyl acetate under the same conditions required 45.85 c.c. $\mathrm{N} / 10 \mathrm{KOH}$.

5. 10 c.c. of the $\mathrm{N} / 40 \mathrm{HCl}$, standardized by weighing the amount of silver chlorid produced, required 2.6 c.c. $\mathrm{N} / 10$ KOIL to neutralize.

Hence:

$64.99-(6.2+8.4)=50.3$

$45.85-(2.6+8.4)=34.85$

$34.85: 50.3: 0.091: \times$.

$\mathrm{x}=0.1313=$ per cent. of free $\mathrm{HICl}$

The sources of error in the Hoffmann method are probably only the following, excluding, of course, the allowable limits of error:

1. Very dilute solutions of hydrochloric acid will give results that are slightly too high on account of the greater dissociation of the acid in dilute solution.

2. The organic acids will also act on the methyl ace- tate to a slight extent, liberating acetic acid, but this will be at most a very slight error, as the relative strength of acetic acid to hydrochloric is as 0.004 to 1 . Lactic acid is as 0.009 to 1 .

3. Neutral salts increase slightly the saponifying power of water, the increase, however, falling within the limits of error.

A table is appended showing the results of a number of comparative tests in which a comparison was made between the results afforded by dimethyl and tropeolin 00 , with the percentage error based on the saponification number as the correct one.

Comparative Table of Tests.*

\begin{tabular}{|c|c|c|c|c|c|}
\hline & $\begin{array}{l}\text { Dimethyl } \\
\text { Titration. }\end{array}$ & $\begin{array}{l}\text { Tropeo- } \\
\text { lin oo. } \\
\text { Titration. }\end{array}$ & $\begin{array}{c}\text { Saponifi- } \\
\text { cation. }\end{array}$ & $\begin{array}{c}\text { Dimethyl } \\
\text { Error }\end{array}$ & $\begin{array}{l}\text { Tropeo- } \\
\text { lin oo. } \\
\text { Errur } \%\end{array}$ \\
\hline 1. & 0.1292 & 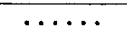 & 0.1063 & +21.54 & $\cdots \cdots \cdots$ \\
\hline 2. & 0.1456 & $\ldots \ldots$ & 0,1233 & +18.08 & ..... \\
\hline 3. & 0.05096 & $\ldots \ldots$ & 0.03387 & +50.16 & $\ldots \ldots$ \\
\hline 4. & 0.1147 & $\ldots \ldots$ & 0.1007 & +13.90 & $\cdots \cdots$ \\
\hline 5. & 0.3722 & $\ldots \ldots$ & 0.3145 & +18.34 & . $\therefore \ldots$ \\
\hline 6. & 0.3640 & $\ldots \ldots$ & 0.2614 & +39.25 & $\ldots \ldots$ \\
\hline 7. & 0.08372 & $\ldots \ldots$ & 0.03819 & +119.2 & $\ldots \ldots$ \\
\hline 8. & 0.02912 & $\ldots \ldots$ & 0.02113 & $\begin{array}{r}+37.81 \\
\end{array}$ & $\cdots \cdots$ \\
\hline 10 & 0.1583 & $\ddot{0} \ddot{109 \dot{2}}$ & 0.1035 & $\begin{array}{r}+52.98 \\
+55.48\end{array}$ & $\ddot{17}$ \\
\hline $\begin{array}{l}10 . \\
11 .\end{array}$ & $\begin{array}{l}0.1729 \\
0.07644\end{array}$ & $\begin{array}{l}0.1092 \\
0.06188\end{array}$ & $\begin{array}{l}0.1112 \\
0.05154\end{array}$ & $\begin{array}{r}+00.48 \\
+48.31\end{array}$ & +20.06 \\
\hline 12. & 0.1565 & 0.091 & 0.0923 & $\begin{array}{r}-69.61 \\
\end{array}$ & -1.14 \\
\hline 13. & 0.2621 & 0.1784 & 0.1577 & +66.22 & +13.73 \\
\hline 14. & 0.0728 & 0.0364 & 0.03832 & +89.98 & -5.01 \\
\hline 15. & 0.1565 & 0.09828 & 0.1132 & $\begin{array}{r}+38.25 \\
\end{array}$ & -13.16 \\
\hline 16. & 0.1820 & 0.1602 & 0.1313 & +38.61 & +22.01 \\
\hline 17. & 0.2038 & 0.1201 & 0.1470 & +38.64 & -18.3 \\
\hline 18. & 0.2348 & 0.1911 & 0.1469 & $\begin{array}{r}+59.83 \\
\end{array}$ & +30.09 \\
\hline 19. & 0.1966 & 0.1656 & 0.1364 & +44.13 & +21.41 \\
\hline 20. & 0.09828 & 0.0637 & 0.0489 & +100.9 & +30.27 \\
\hline 21. & 0.1383 & 0.0582 & 0.0973 & +42.14 & -40.19 \\
\hline 22. & 0.1966 & 0.1529 & 0.1374 & +43.08 & +11.28 \\
\hline $2 \overline{3}$. & 0.0546 & 0.04368 & 0.0339 & +61.06 & +28.85 \\
\hline 24. & 0.0728 & 0.03276 & 0.0232 & +213.80 & +41.21 \\
\hline 25 . & 0.2621 & 0.2475 & 0.2140 & +22.48 & +15.65 \\
\hline 26. & 0.2366 & 0.2002 & 0.1630 & +45.15 & $\begin{array}{r}+22.82 \\
\end{array}$ \\
\hline 27. & 0.1511 & 0.1183 & 0.1076 & +40.42 & +9.94 \\
\hline 28. & 0.2912 & 0.1711 & 0.1919 & +51.75 & -10.84 \\
\hline 29 . & 0.1165 & 0.0728 & 0.08302 & +40.32 & --12.31 \\
\hline 30. & 0.2621 & $0: 2330$ & 0.1866 & +40.46 & +24.86 \\
\hline 31. & 0.1241 & 0.0584 & 0.06615 & +87.62 & -11.71 \\
\hline 32. & 0.0546 & & 0.01433 & +281.00 & \\
\hline 33. & 0.1529 & 0.08008 & 0.09272 & +64.91 & -13.63 \\
\hline 34. & 0.1674 & 0.091 & 0.1347 & +24.28 & -32.44 \\
\hline 35. & 0.1820 & 0.1274 & 0.1256 & $\begin{array}{r}+44.90 \\
\end{array}$ & +1.43 \\
\hline 36. & 0.3349 & & 0.1960 & +70.87 & \\
\hline 37. & 0.1674 & 0.1274 & 0.099 & +69.10 & +2869 \\
\hline 38. & 0.2330 & 0.1820 & 0.1486 & +56.78 & $\begin{array}{r}+22.47 \\
\end{array}$ \\
\hline 39. & 0.1674 & 0.1602 & 0.1313 & +27.49 & +22.01 \\
\hline
\end{tabular}

\section{A CASE OF CHOLESTERIN STONES IN THE BRAIN AND CORD.*}

\section{F. F. SOUTHARD, M.D.}

Tnstructor in Neuropathology and Charles Eliot Ware Fellow, Harvard University Medical School. BOSTON.

Following is a case of multiple cholesterin concretions found at autopsy in the brain and cord of a man who showed in life no signs referable thereto. About the masses there was a fibrillary overgrowth of neuroglia.

The patient was under clinical observation at the Boston City Hospital for a little over three weeks in the spring of 1904, on the medical service of Dr. C. F. Withington, whom I wish to thank for the use of his records. The patient was a man of 56 , with extensive peripheral arteriosclerosis. For the most part he presented a plain history of cardiac disease growing worse: orthopnea, dyspnea, cyanosis, edema, all coming on in irregular spells, together with gradual enlargement of the heart area and feebleness of heart action, slight albuminuria, a fairly constant demonstration of a soft blowing systolic murmur at the apex transmitted to the axilla, and gradual development of dullness in lower

- From the Pathological Laboratory of the Boston City Hospital.

* Read in the Section on Pathology and Physiology of the American Medical Association, at the Fifty-sixth Annual Session, July, 1905 . 